\title{
In vitro nutritional requirements and metabolic products of pathogenic and nonpathogenic strains of Cryptobia salmositica: essential carbohydrates and amino acids
}

\author{
B. F. Ardelli ${ }^{1,2}$, P. T. K. Woo ${ }^{1, *}$ \\ ${ }^{1}$ Department of Zoology and Axelrod Institute of Ichthyology, University of Guelph, Guelph, Ontario N1G 2W1 Canada \\ ${ }^{2}$ Present address: Institute of Parasitology, McGill University, 21-111 Lakeshore Road, Ste-Anne de Bellevue, Quebec, \\ H9X 3V9 Canada
}

\begin{abstract}
Pathogenic and nonpathogenic strains of Cryptobia salmositica cultured in minimum essential medium (MEM) with several monosaccharides, disaccharides and amino acids were observed for differences in multiplication and motility. Metabolic end products (i.e. alanine, aspartate, carbon dioxide, lactate and pyruvate) were measured for logarithmically growing cells under aerobic conditions. The pathogenic strain of $C$. salmositica multiplied more readily in MEM supplemented with $\mathrm{D}(-)$ ribose, $\mathrm{D}(+)$ xylose, $\mathrm{D}(+)$ galactose, $\mathrm{D}(+)$ glucose, $\mathrm{D}(+)$ mannose and $\mathrm{D}(-)$ fructose. However, there were no significant differences in multiplication when the strains were cultured with the monosaccharide $\mathrm{D}(-)$ arabinose. The nonpathogenic strain multiplied significantly better than the pathogenic strain in the presence of the disaccharides $\alpha$-lactose, maltose and sucrose. It also multiplied more readily when the amino acids L-glutamine and $\mathrm{D}(-)$ proline were added to MEM. The end products of carbohydrate catabolism under aerobic conditions were alanine, aspartate, carbon dioxide, lactate and pyruvate.
\end{abstract}

KEY WORDS: Cryptobia · Carbohydrates · Growth rate

Resale or republication not permitted without written consent of the publisher

\section{INTRODUCTION}

Cryptobia salmositica is a hemoflagellate transmitted by the rhynchobdellid leech Piscicola salmositica. It causes cryptobiosis in economically important fishes (Oncorhynchus spp.) on the west coast of North America (Woo \& Poynton 1995).

To date, few studies of the biological and biochemical characteristics of this group of flagellates have been conducted. The pathogen has organelles typical of the parasitic Kinetoplastida, which includes a kinetoplast, well-developed mitochondrion (Paterson \& Woo 1983) and glycosomes (Ardelli et al. 2000). It undergoes aerobic respiration under in vitro conditions (Thomas et al. 1992, Ardelli \& Woo 2001a), utilizes Lglutamine and glucose during multiplication, and addition of fetal bovine serum (FBS) enhances multiplication (Ardelli \& Woo 1998, 2001b).

Cryptobia salmositica has been attenuated through continuous in vitro culture (Woo \& Li 1990). Several studies have been conducted to elucidate some of the basic biological differences between the 2 strains of C. salmositica. Woo \& Thomas (1991) demonstrated that the nonpathogenic strain had 5 fewer polypeptides and some of the remaining polypeptides were antigenically distinct from those of the pathogen (Woo \& Thomas 1991). The pathogenic strain of C. salmositica produces both cysteine protease and metalloprotease under both in vitro and in vivo conditions (Zuo \& Woo 1997). The metalloprotease has been isolated and purified and it digests several proteins, including the membranes of erythrocytes. After prolonged in vitro 
culture, the pathogenic strain ceases to secrete the metalloprotease. The metalloprotease contributes to the mechanism of anaemia and, after prolonged culture, the pathogen is still infective to fishes but no longer causes disease. This is similar to the nonpathogenic strain, which does not produce metalloprotease, but is still infective to fishes and is used as a live vaccine (Li \& Woo 1995).

Despite the evidence that has been presented, relatively few biological differences have been detected between the 2 strains of Cryptobia salmositica. Studies by Ardelli et al. (2000) focussed on glycosomes and glycolysis in the 2 strains and showed that both strains have a similar number of glycosomes. Also, the mobilities and staining patterns of several glycolytic enzymes and the activities of lactate dehydrogenase were similar.

The main objective of the present study was to determine if the pathogenic and nonpathogenic strains of Cryptobia salmositica have different preferences for their carbon and energy sources. To do this, parasites were incubated in a variety of monosaccharides, disaccharides and amino acids. We were also interested in looking at the metabolic pathways that were functioning within the parasite. Measuring the production of alanine, aspartate, carbon dioxide, lactate and pyruvate after incubation in the various carbohydrates and amino acids might provide some insight into which pathways were functioning. By measuring the end products of metabolism as well as carbohydrate utilization, it was hoped that the study would reveal some basic biological differences between the 2 strains of the parasite that would help in understanding the mechanism of disease in infected fishes.

\section{MATERIALS AND METHODS}

In vitro culture of Cryptobia salmositica. A cloned strain of pathogenic C. salmositica was used to infect rainbow trout Oncorhynchus mykiss. The strain was initially isolated from the leech Piscicola salmositica, and details of the cloning of the parasite (Woo 1979) and fish maintenance (Ardelli \& Woo 1998) have already been described. The pathogenicity of $C$. salmositica is maintained by serial passage in rainbow trout. To culture the pathogen, blood was withdrawn aseptically from an infected trout and inoculated into sterile culture flasks containing minimum essential medium (MEM) supplemented with Hanks' salts, $100 \mathrm{mg} \mathrm{ml}^{-1}$ L-glutamine, $10 \mathrm{mg} \mathrm{ml}^{-1}$ phenol red and $25 \%$ heat-inactivated FBS, pH 7.3. The nonpathogenic C. salmositica was attenuated through serial in vitro culture and maintained in MEM (Woo \& Li 1990). It was isolated and cloned in 1989, and is infective to trout but does not cause disease (Li \& Woo 1995).

Experimental design. We devided 260 tissue culture flasks into 2 groups (Groups A and $\mathrm{B} ; \mathrm{n}=140$ per group). Flasks in Group A contained $30.0 \mathrm{ml}$ of MEM supplemented with Hanks' salts, 25 mM HEPES and $25 \%$ FBS, and flasks in Group B contained MEM supplemented as for Group A but without FBS. The flasks were then further divided into 13 subgroups ( $\mathrm{n}=10$ per subgroup) and each was supplemented with $5 \mathrm{mg} \mathrm{ml}^{-1}$ of each of the following: Subgroups A1 and B1 with $\mathrm{D}(-)$ arabinose; $\mathrm{A} 2$, B2 with $\mathrm{D}(-)$ ribose; A3, B3 with $\mathrm{D}(+)$ xylose; A4, B4 with $\mathrm{D}(+)$ galactose; A5, B5 with $\mathrm{D}(+)$ glucose; A6, B6 with $\mathrm{D}(+)$ mannose; A7, B7 with $\mathrm{D}(-)$ fructose; A8, B8 with $\alpha-\mathrm{D}(+)$ glucose; A9, B9 with $\alpha-$ lactose; A10, B10 with maltose; A11, B11 with sucrose; A12, B12 with L-glutamine; A13, B13 with proline (see Tables 1 \& 2). Each subgroup was then divided into 2 further subgroups ( $\mathrm{n}=5$ per group), 1 of which was inoculated with 100000 pathogenic Cryptobia salmositica and the other with 100000 nonpathogenic $C$. salmositica. Flasks were sampled weekly (100 $\mu \mathrm{l})$ and the number of parasites was counted using a hemocytometer (Archer 1965).

During the log phase of growth (Week 7), $2.5 \mathrm{ml}$ of MEM was removed from each flask and the parasites were separated from the MEM by centrifugation. Parasites were washed 3 times in cold-blooded vertebrate Ringer's (CBVR) solution and diluted to a final concentration of 500000 parasites in $10.0 \mu \mathrm{l}$ of CBVR. The washed parasites were incubated in $3.0 \mathrm{ml}$ of MEM (specific for each substrate) for $24 \mathrm{~h}$ and the activities of glutamic pyruvic transaminase (alanine aminotransferase), glutamic oxalacetic transaminase (aspartate aminotransferase), carbon dioxide, lactate and pyruvate were then determined.

Enzyme assays. Glutamic pyruvic transaminase (GPT): Alanine aminotransferase catalyses the transfer of $\alpha$-amino groups from alanine to $\alpha$-ketoglutaric acid to yield glutamic acid and pyruvic acid. The pyruvic acid that forms reacts with 2,4-dinitrophenylhydrazine, and the color intensity of the resulting pheylhydrazone is measured. A calibration curve was prepared and used to calculate GPT activities. We put $1 \mathrm{ml}$ of substrate $\left(1.5 \mathrm{mmol} \mathrm{l}^{-1}\right.$ sodium pyruvate in phosphate buffer; $\mathrm{pH} 7.5$ ) into a test tube and placed this in a $37^{\circ} \mathrm{C}$ water bath. Once warmed, $0.2 \mathrm{ml}$ of MEM was added and the test tube was placed in a water bath (with shaking) $\left(37^{\circ} \mathrm{C}\right.$ ) for $30 \mathrm{~min}$. After $30 \mathrm{~min}, 1 \mathrm{ml}$ of $20 \mathrm{mg} \mathrm{dl}^{-1}$ of 2,4-dinitrophenylhydrazine in acid solution was added, mixed and left at room temperature for $20 \mathrm{~min}$. Next, $10 \mathrm{ml}$ of $0.4 \mathrm{~N} \mathrm{NaOH}$ was added, mixed and incubated for $5 \mathrm{~min}$ at room temperature. GPT activity was calculated using the calibration curve and expressed in $\mathrm{U} \mathrm{ml}^{-1}$ (Frankel 1970).

Glutamic oxalacetic transaminase (GOT): The prin- 
ciple for determining GOT is similar to that for determining GPT. GOT catalyses the transfer of $\alpha$-amino groups from aspartic acid to $\alpha$-ketoglutaric acid to yield glutamic acid and oxalacetic acid. The oxalacetic acid that forms reacts with 2,4-dinitrophenylhydrazine, and the color intensity of the resulting phenylhydrazones is proportional to the transaminase activity. A calibration curve was prepared and used to calculate GOT activities. We put $1 \mathrm{ml}$ of substrate containing $0.2 \mathrm{~mol} \mathrm{l}^{-1}$ DL-aspartate and $1.8 \mathrm{mmol} \mathrm{l}^{-1} \alpha$ ketoglutaric acid in phosphate buffer $(\mathrm{pH}$ 7.5) into a test tube, which was placed in a $37^{\circ} \mathrm{C}$ water bath (with shaking) for $1 \mathrm{~h}$. After $1 \mathrm{~h}, 1 \mathrm{ml}$ of $20 \mathrm{mg} \mathrm{dl}^{-1}$ of 2, 4 dinotrophenylhydrazine in acid solution was added, mixed and left at room temperature for $20 \mathrm{~min}$. Next, $10.0 \mathrm{ml}$ of $0.40 \mathrm{~N} \mathrm{NaOH}$ was added, mixed and incubated for $5 \mathrm{~min}$. GOT activity was calculated using the calibration curve and expressed as $\mathrm{U} \mathrm{ml}^{-1}$ (Frankel 1970).

Dissolved carbon dioxide: Phosphoenol pyruvate carboxylase (PEPC) catalyses the reaction between phosphoenol pyruvate and carbon dioxide (bicarbonate) to form oxalacetate and phosphate ion. In the reaction catalysed by malate dehydrogenase (MDH), oxalacetate is reduced to malate with simultaneous oxidation of an equimolar amount of reduced nicotinamide adenine dinucleotide (NADH) to NAD. This results in a decrease in absorbance at $340 \mathrm{~nm}$ which is directly proportional to the carbon dioxide concentration in the sample. We prepared 2 solutions (A and B). Solution A contained $2.2 \mathrm{mmol} \mathrm{l}^{-1}$ phosphoenol pyruvate, $0.32 \mathrm{mmol} \mathrm{l}^{-1} \mathrm{NADH}$ and $10 \mathrm{mmol} \mathrm{l}^{-1}$ phosphate buffer (pH 8.0). Solution B contained $2750 \mathrm{U} \mathrm{l}^{-1}$ PEPC, $15400 \mathrm{U} \mathrm{l}^{-1} \mathrm{MDH}$ and $10 \mathrm{mmol} \mathrm{l}^{-1}$ magnesium in phosphate buffer (pH 6.5). We added $1.0 \mathrm{ml}$ of Solution B to $10 \mathrm{ml}$ of Solution A. All reagents were warmed to $37^{\circ} \mathrm{C}$ before use. An aliquot of $1.0 \mathrm{ml}$ of the mixed solution was pipetted into a cuvette and $5.0 \mu \mathrm{l}$ of sample were added. After incubation for $5 \mathrm{~min}$, absorbance was read at $340 \mathrm{~nm}$ (Forrester et al. 1976).

Lactate: Lactate was determined enzymatically (Marbach \& Weil 1967) on the principle that lactic acid is converted to pyruvate and hydrogen peroxide by lactate oxidase. In the presence of the hydrogen peroxide thus formed, peroxidase catalyzes the oxidative condensation of chromogen precursors to produce a colored dye with an absorption maximum at $540 \mathrm{~nm}$. The increase in absorbance at $540 \mathrm{~nm}$ is directly proportional to the lactate concentration in the sample. To determine lactate, $1.0 \mathrm{ml}$ of a solution containing $400 \mathrm{U} \mathrm{l}^{-1}$ of lactate oxidase, 2400 $\mathrm{U} \mathrm{l}^{-1}$ horseradish peroxidase and chromogen precursors in $0.2 \mathrm{M}$ glycine buffer (Sigma) was pipetted into a cuvette; $10 \mu \mathrm{l}$ of MEM were added and allowed to react with the lactate mixture for $20 \mathrm{~min}$. Absorbance was read at $540 \mathrm{~nm}$ using water as reference.
Statistical analysis: To analyse the effects of carbohydrates on parasite multiplication, a repeated measures analysis of variance (RM-ANOVA) was used. The factors time and treatment were considered for each experimental group. When the treatment effects were not normally distributed, a Friedman RMANOVA on ranks was used. A 2-way ANOVA was used to test the hypothesis of no differences between the groups, but it was not able to determine which groups were different or the extent of these differences. A Tukey multiple-comparison test was used to isolate the differences by performing comparisons between the experimental groups. The Tukey test was used for multiple comparisons because it controls the errors of all comparisons simultaneously and is therefore less likely to determine that a difference is statistically significant. Significance was evaluated at $p$ " 0.05 .

Pyruvate: Pyruvate was determined enzymatically (Marbach \& Weil 1967) by the oxidation of reduced nicotinamide-adenine dinucleotide (NAD) in the presence of lactate dehydrogenase at $\mathrm{pH}$ 7.0. We pipetted $2 \mathrm{ml}$ of MEM into a centrifuge tube containing $4.0 \mathrm{ml}$ of cold $8 \%$ perchloric acid to precipitate proteins. Proteins were removed by centrifugation for $3 \mathrm{~min}$ at $10000 \times g$, and $2.0 \mathrm{ml}$ of supernatant was added to a cuvette containing $0.5 \mathrm{ml}$ of $1.5 \mathrm{M}$ Tris buffer. After mixing, $0.5 \mathrm{ml}$ of $1.0 \mathrm{mg} \mathrm{ml}^{-1}$ of NADH was added and absorbance read at $340 \mathrm{~nm}$ against water as reference. Lactate dehydrogenase $\left(0.05 \mathrm{ml} 1000 \mathrm{U} \mathrm{ml}^{-1}\right)$ was added, and the decrease in absorbance read at $340 \mathrm{~nm}$.

\section{RESULTS}

\section{Multiplication and motility}

Neither strain multiplied in media that did not contain serum supplement. As a result, no further analyses (i.e. production of alanine, aspartate, carbon dioxide, lactate, pyruvate) were performed. In general, the pathogenic strain of Cryptobia salmositica multiplied more readily in MEM containing monosaccharides than in media containing either disaccharides or amino acids. The pathogenic strain multiplied better in ribose, xylose, galactose, D-glucose and mannose. The exception was $\beta-\mathrm{D}(+)$ glucose, in which the nonpathogenic strain multiplied better than the pathogenic strain between 8 and $10 \mathrm{wk}$ after inoculation; however, the results were not significant $(p=0.325)$. There were no significant differences between the 2 strains when incubated in the monosaccharides arabinose $(p=$ $0.8475)$ or fructose $(p=0.955)$. Significant differences were detected between the 2 strains when incubated 
in ribose $(p=0.0231)$ and galactose $(p=0.0332)$. The numbers of pathogenic organisms were higher than those of nonpathogenic organisms in ribose, xylose, galactose, D-glucose and mannose between 6 and 10 wk after inoculation. Both the pathogenic and nonpathogenic strain, were active and motile in media containing monosaccharides (Fig. 1). In media containing monosaccharides, but with no serum supplement, neither strain multiplied.

In contrast, the nonpathogenic strain, in general, multiplied better than the pathogenic strain in media containing disaccharides. These results were significant when the parasites were incubated with lactose $(p=0.022)$, maltose $(p=0.036)$ or sucrose $(p=0.033)$. Both strains of the parasite were active and motile in media containing disaccharides and serum supplement; however, neither strain multiplied in media containing disaccharides alone (Fig. 2).

Both strains of Cryptobia salmositica multiplied in media supplemented with the amino acids L-glutamine or D-proline and serum (Fig. 3). Parasites did not multiply in medium containing only amino acids. The nonpathogenic strain multiplied more readily than the pathogenic strain in both L-glutamine and D-proline. The results were significant for L-glutamine $(p=0.031)$ but not for D-proline ( $p=0.201$ ) (Fig. 3).

\section{End products of metabolism}

The end products of metabolism that were produced after incubation in various monosaccharides, disaccharides and amino acids were measured and then analysed for significance using a RM-ANOVA. A significant difference was not detected between the various end products produced by either strain.

\section{Monosaccharides}

$D(-)$ arabinose. The products alanine, aspartate, carbon dioxide and pyruvate were detectable in both strains of Cryptobia salmositica when incubated in arabinose. Lactate was not detectable in either strain. Higher levels of alanine, aspartate and carbon dioxide were produced by the pathogenic strain, while the nonpathogenic strain produced higher levels of pyruvate (Table 1).

$D(-)$ ribose. Both strains produced aspartate, carbon dioxide, lactate and pyruvate, while alanine was only produced by the pathogenic strain. More alanine $(\mathrm{p}=$ $0.0000)$ and lactate $(p=0.0000)$ were produced by the pathogenic strain, while more aspartate and pyruvate were produced by the nonpathogenic strain. The non-
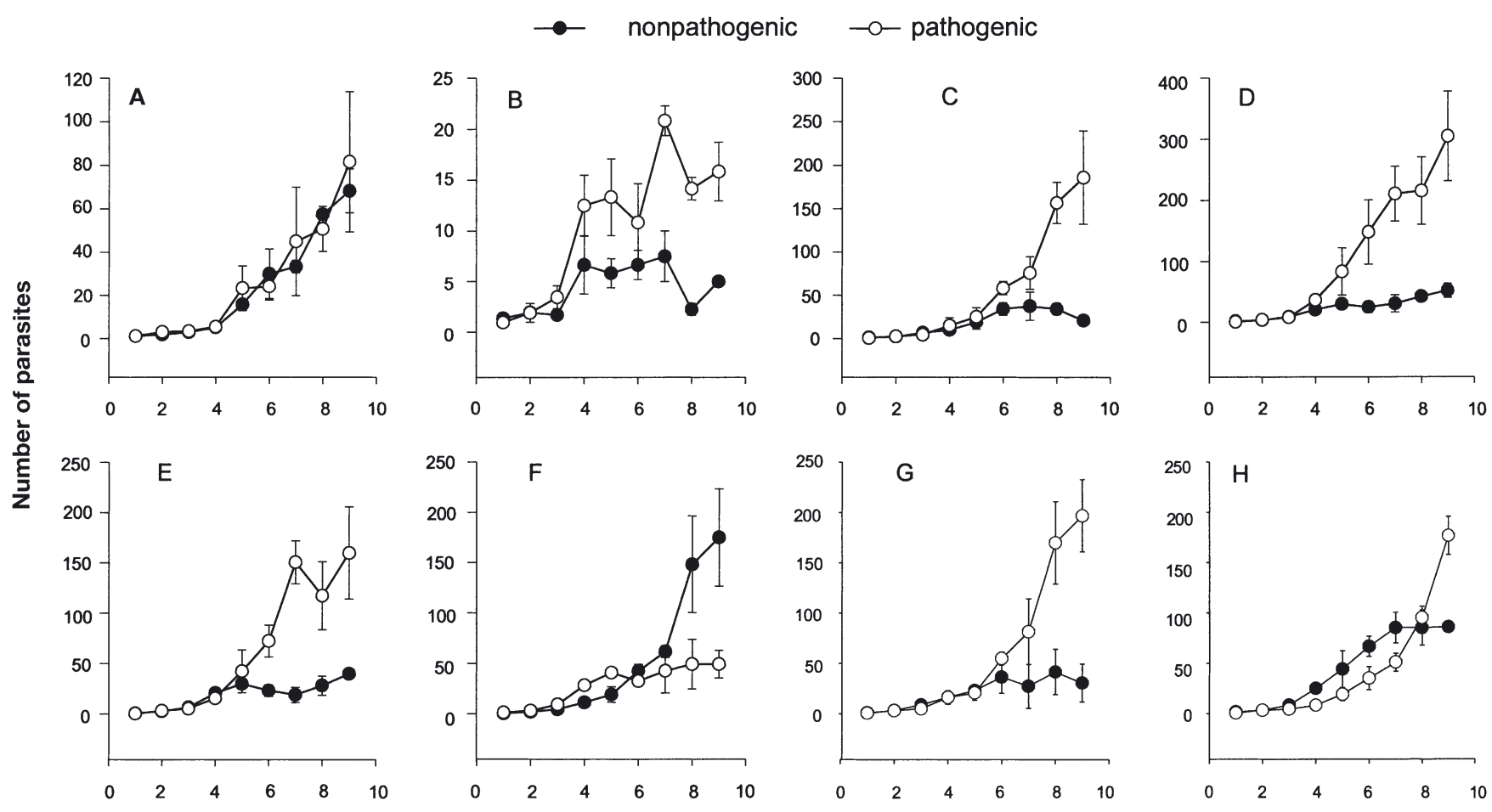

Weeks in culture

Fig. 1. Cryptobia salmositica. Growth rates of pathogenic and nonpathogenic strains in medium supplemented with monosaccharides; (A) arabinose, (B) ribose, (C) xylose, (D) galactose, (E) D-glucose, (F) $\beta$-D $(+)$ glucose, (G) mannose, (H) fructose 


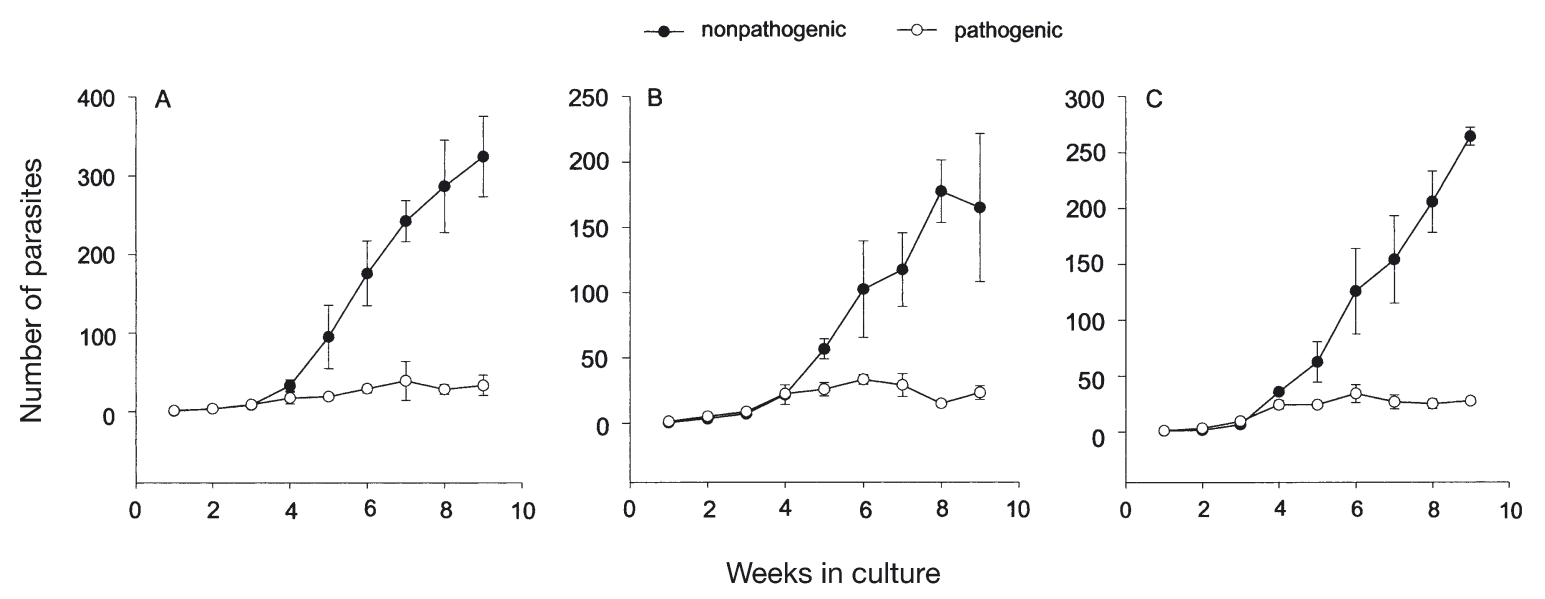

Fig. 2. Growth rates of pathogenic and nonpathogenic strains in medium supplemented with disaccharides; (A) lactose, (B) maltose, (C) sucrose

pathogenic Cryptobia salmositica produced more carbon dioxide than the pathogenic strain, but this was not significant (Table 1).

$D(+) x y l o s e$. Alanine, aspartate, carbon dioxide, lactate and pyruvate were produced by both strains when incubated in the monosaccharide xylose. More alanine, aspartate and lactate were produced by the pathogenic strain, while more carbon dioxide and pyruvate were produced by the nonpathogenic strain (Table 1).

$D(+)$ galactose. Alanine, aspartate, carbon dioxide, lactate and pyruvate were produced by pathogenic and nonpathogenic Cryptobia salmositica incubated in $\mathrm{D}(+)$ galactose. The pathogenic strain produced greater amounts of alanine, aspartate, carbon dioxide, lactate and pyruvate than the nonpathogenic strain (Table 1).

$D(+)$ glucose. Alanine, aspartate and pyruvate were produced by pathogenic and nonpathogenic strains when incubated in medium supplemented with $\mathrm{D}(+)$ glucose. Lactate was not detected in either strain, and only the pathogenic strain of Cryptobia salmositica produced carbon dioxide. The amounts of alanine and aspartate produced by the nonpathogenic strain were higher than those produced by the pathogenic strain, but pyruvate levels were higher in the pathogenic strain (Table 1).

$\beta$ - $D(+)$ glucose. Alanine, aspartate, lactate and pyruvate were produced by both strains after incubation for $48 \mathrm{~h}$ in medium containing $\beta$-D(+)glucose. The nonpathogenic strain produced more alanine, aspartate, carbon dioxide and lactate, while the pathogenic strain produced more pyruvate (Table 2). Carbon dioxide was not produced (or was below detectable levels) by the pathogenic strain after incubation in medium supplemented with glucose.

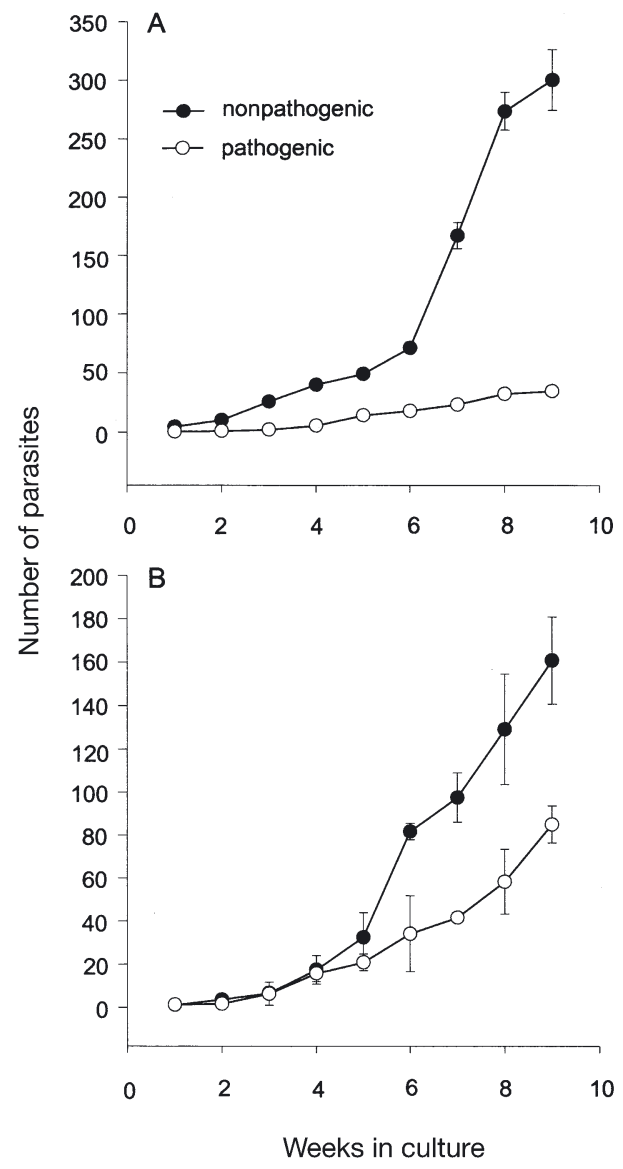

Fig. 3. Growth rates in amino acids. (A) L-glutamine, (B) proline

$D(+)$ mannose. Alanine, aspartate, carbon dioxide, lactate and pyruvate were produced by both the pathogenic and nonpathogenic strains of Cryptobia salmo- 
Table 1. Cryptobia salmositica. End products of carbohydrate metabolism in pathogenic (P) and nonpathogenic (NP) strains after incubation in medium containing monosaccharides. Values ( $\mu \mathrm{g}$ parasite ${ }^{-1}$ ) are means (SD) of 5 samples. nd: not detected

\begin{tabular}{|c|c|c|c|c|c|c|c|c|c|c|}
\hline \multirow[t]{2}{*}{ Carbohydrate } & \multicolumn{2}{|c|}{ Alanine } & \multicolumn{2}{|c|}{ Aspartate } & \multicolumn{2}{|c|}{ Carbon dioxide } & \multicolumn{2}{|c|}{ Lactate } & \multicolumn{2}{|c|}{ Pyruvate } \\
\hline & $\mathrm{P}$ & NP & $\mathrm{P}$ & NP & $\mathrm{P}$ & NP & $\mathrm{P}$ & NP & $\mathrm{P}$ & NP \\
\hline D(-)arabinose & $\begin{array}{c}0.03 \\
(0.03)\end{array}$ & $\begin{array}{c}0.01 \\
(0.006)\end{array}$ & $\begin{array}{c}0.04 \\
(0.02)\end{array}$ & $\begin{array}{c}0.02 \\
(0.005)\end{array}$ & $\begin{array}{c}0.02 \\
(0.02)\end{array}$ & $\begin{array}{c}0.02 \\
(0.008)\end{array}$ & nd & nd & $\begin{array}{c}0.09 \\
(0.01)\end{array}$ & $\begin{array}{c}0.03 \\
(0.03)\end{array}$ \\
\hline $\mathrm{D}(-)$ ribose & $\begin{array}{c}0.05 \\
(0.03)\end{array}$ & nd & $\begin{array}{c}0.07 \\
(0.04)\end{array}$ & $\begin{array}{c}0.05 \\
(0.05)\end{array}$ & $\begin{array}{l}0.29 \\
(0.1)\end{array}$ & $\begin{array}{c}0.74 \\
(0.33)\end{array}$ & $\begin{array}{c}17.79 \\
(11.51)\end{array}$ & $\begin{array}{c}0.91 \\
(0.91)\end{array}$ & $\begin{array}{c}0.23 \\
(0.13)\end{array}$ & $\begin{array}{c}0.003 \\
(0.003)\end{array}$ \\
\hline $\mathrm{D}(+) x y l o s e$ & $\begin{array}{c}0.06 \\
(0.01)\end{array}$ & $\begin{array}{c}0.05 \\
(0.03)\end{array}$ & $\begin{array}{c}0.09 \\
(0.03)\end{array}$ & $\begin{array}{c}0.05 \\
(0.02)\end{array}$ & $\begin{array}{c}0.25 \\
(0.06)\end{array}$ & $\begin{array}{c}0.37 \\
(0.22)\end{array}$ & $\begin{array}{l}13.76 \\
(8.42)\end{array}$ & $\begin{array}{c}3.45 \\
(0.87)\end{array}$ & $\begin{array}{c}0.1 \\
(0.1)\end{array}$ & $\begin{array}{c}0.16 \\
(0.01)\end{array}$ \\
\hline $\mathrm{D}(+)$ galactose & $\begin{array}{c}0.03 \\
(0.02)\end{array}$ & $\begin{array}{c}0.02 \\
(0.01)\end{array}$ & $\begin{array}{c}0.02 \\
(0.004)\end{array}$ & $\begin{array}{c}0.01 \\
(0.01)\end{array}$ & $\begin{array}{c}0.01 \\
(0.01)\end{array}$ & $\begin{array}{c}0.008 \\
(0.008)\end{array}$ & $\begin{array}{c}2.09 \\
(1.11)\end{array}$ & $\begin{array}{c}0.75 \\
(0.38)\end{array}$ & $\begin{array}{c}0.09 \\
(0.02)\end{array}$ & $\begin{array}{c}0.07 \\
(0.01)\end{array}$ \\
\hline $\mathrm{D}(+)$ glucose & $\begin{array}{c}0.01 \\
(0.009)\end{array}$ & $\begin{array}{c}0.03 \\
(0.007)\end{array}$ & $\begin{array}{c}0.02 \\
(0.003)\end{array}$ & $\begin{array}{c}0.05 \\
(0.01)\end{array}$ & $\begin{array}{c}0.004 \\
(0.004)\end{array}$ & nd & nd & nd & $\begin{array}{c}0.13 \\
(0.05)\end{array}$ & $\begin{array}{c}0.09 \\
(0.06)\end{array}$ \\
\hline$\beta$-D $(+) g l u c o s e$ & $\begin{array}{c}0.03 \\
(0.006)\end{array}$ & $\begin{array}{c}0.06 \\
(0.02)\end{array}$ & $\begin{array}{c}0.04 \\
(0.02)\end{array}$ & $\begin{array}{c}0.05 \\
(0.04)\end{array}$ & nd & $\begin{array}{c}0.05 \\
(0.08)\end{array}$ & $\begin{array}{c}0.89 \\
(0.41)\end{array}$ & $\begin{array}{c}3.7 \\
(3.7)\end{array}$ & $\begin{array}{c}0.13 \\
(0.06)\end{array}$ & $\begin{array}{c}0.12 \\
(0.05)\end{array}$ \\
\hline $\mathrm{D}(+)$ mannose & $\begin{array}{c}0.09 \\
(0.03)\end{array}$ & $\begin{array}{c}0.04 \\
(0.03)\end{array}$ & $\begin{array}{c}0.16 \\
(0.05)\end{array}$ & $\begin{array}{c}0.11 \\
(0.05)\end{array}$ & $\begin{array}{c}0.27 \\
(0.05)\end{array}$ & $\begin{array}{c}0.53 \\
(0.15)\end{array}$ & $\begin{array}{l}10.93 \\
(4.04)\end{array}$ & $\begin{array}{l}3.54 \\
(0.5)\end{array}$ & $\begin{array}{c}0.26 \\
(0.06)\end{array}$ & $\begin{array}{c}0.26 \\
(0.19)\end{array}$ \\
\hline D(-)fructose & $\begin{array}{c}0.1 \\
(0.07)\end{array}$ & $\begin{array}{c}0.02 \\
(0.005)\end{array}$ & $\begin{array}{c}0.04 \\
(0.02)\end{array}$ & $\begin{array}{c}0.03 \\
(0.003)\end{array}$ & $\begin{array}{c}0.04 \\
(0.02)\end{array}$ & $\begin{array}{c}0.02 \\
(0.001)\end{array}$ & $\begin{array}{c}5.15 \\
(2.59)\end{array}$ & $\begin{array}{c}0.72 \\
(0.11)\end{array}$ & $\begin{array}{c}0.07 \\
(0.01)\end{array}$ & $\begin{array}{c}0.1 \\
(0.06)\end{array}$ \\
\hline
\end{tabular}

Table 2. Cryptobia salmositica. End products of carbohydrate metabolism in pathogenic (P) and nonpathogenic (NP) strains after incubation in medium containing disaccharides and amino acids. Values ( $\mu$ g parasite ${ }^{-1}$ ) are means (SD) of 5 samples. nd: not detected

\begin{tabular}{|c|c|c|c|c|c|c|c|c|c|c|}
\hline \multirow{2}{*}{ Supplement } & \multicolumn{2}{|c|}{ Alanine } & \multicolumn{2}{|c|}{ Aspartate } & \multicolumn{2}{|c|}{ Carbon dioxide } & \multicolumn{2}{|c|}{ Lactate } & \multicolumn{2}{|c|}{ Pyruvate } \\
\hline & $\mathrm{P}$ & NP & $\mathrm{P}$ & NP & $\mathrm{P}$ & NP & $\mathrm{P}$ & NP & $\mathrm{P}^{1}$ & NP \\
\hline \multicolumn{11}{|l|}{ Carbohydrate } \\
\hline$\alpha$-lactose & $\begin{array}{c}0.03 \\
(0.02)\end{array}$ & $\begin{array}{c}0.014 \\
(0.015)\end{array}$ & $\begin{array}{c}0.06 \\
(0.05)\end{array}$ & $\begin{array}{c}0.03 \\
(0.01)\end{array}$ & $\begin{array}{c}0.11 \\
(0.09)\end{array}$ & $\begin{array}{c}0.02 \\
(0.02)\end{array}$ & $\begin{array}{c}2.11 \\
(1.03)\end{array}$ & $\begin{array}{c}0.6 \\
(0.82)\end{array}$ & $\begin{array}{c}0.1 \\
(0.18)\end{array}$ & $\begin{array}{c}0.04 \\
(0.02)\end{array}$ \\
\hline Maltose & $\begin{array}{c}0.06 \\
(0.02)\end{array}$ & $\begin{array}{c}0.04 \\
(0.03)\end{array}$ & $\begin{array}{c}0.14 \\
(0.04)\end{array}$ & $\begin{array}{c}0.04 \\
(0.02)\end{array}$ & $\begin{array}{c}0.34 \\
(0.08)\end{array}$ & $\begin{array}{c}0.03 \\
(0.02)\end{array}$ & $\begin{array}{c}2.1 \\
(0.72)\end{array}$ & $\begin{array}{c}2.64 \\
(1.86)\end{array}$ & $\begin{array}{c}0.12 \\
(0.11)\end{array}$ & $\begin{array}{c}0.08 \\
(0.02)\end{array}$ \\
\hline Sucrose & $\begin{array}{c}0.03 \\
(0.02)\end{array}$ & $\begin{array}{c}0.02 \\
(0.01)\end{array}$ & $\begin{array}{c}0.02 \\
(0.02)\end{array}$ & $\begin{array}{c}0.02 \\
(0.005)\end{array}$ & $\begin{array}{c}0.27 \\
(0.04)\end{array}$ & $\begin{array}{c}0.11 \\
(0.03)\end{array}$ & $\begin{array}{c}3.34 \\
(0.65)\end{array}$ & $\begin{array}{c}5.31 \\
(2.38)\end{array}$ & $\begin{array}{c}0.12 \\
(0.08)\end{array}$ & $\begin{array}{c}0.07 \\
(0.03)\end{array}$ \\
\hline \multicolumn{11}{|l|}{ Amino acid } \\
\hline $\mathrm{D}(-)$ proline & $\begin{array}{c}0.01 \\
(0.008)\end{array}$ & $\begin{array}{c}0.06 \\
(0.05)\end{array}$ & $\begin{array}{c}0.02 \\
(0.003)\end{array}$ & $\begin{array}{c}0.02 \\
(0.03)\end{array}$ & $\begin{array}{l}0.012 \\
(0.01)\end{array}$ & $\begin{array}{c}0.08 \\
(0.05)\end{array}$ & nd & nd & $\begin{array}{c}0.06 \\
(0.02)\end{array}$ & $\begin{array}{c}0.06 \\
(0.03)\end{array}$ \\
\hline L(-)glutamine & $\begin{array}{c}0.004 \\
(0.005)\end{array}$ & $\begin{array}{c}0.003 \\
(0.004)\end{array}$ & $\begin{array}{c}0.002 \\
(0.004)\end{array}$ & $\begin{array}{c}0.004 \\
(0.005)\end{array}$ & nd & $\begin{array}{l}0.008 \\
(0.01)\end{array}$ & $\begin{array}{c}0.003 \\
(0.006)\end{array}$ & $\begin{array}{c}0.01 \\
(0.009)\end{array}$ & nd & $\begin{array}{c}0.0004 \\
(0.0009)\end{array}$ \\
\hline
\end{tabular}

sitica when incubated in medium supplemented with $\mathrm{D}(+)$ mannose. The amounts of alanine, aspartate and lactate produced were greater in the pathogenic strain than the nonpathogenic strain. The quantities of carbon dioxide produced by the nonpathogenic strain were higher than those of the pathogenic strain (Table 1); however, there was no difference in the pyruvate levels between the 2 strains.

$D(-)$ fructose. Alanine, aspartate, carbon dioxide, lactate and pyruvate were produced by both strains when incubated in medium supplemented with $\mathrm{D}(-)$ fructose. The pathogenic strain of Cryptobia salmositica produced more aspartate, carbon dioxide, lactate and pyruvate (Table 1).

\section{Disaccharides}

$\alpha$-lactose. The products alanine, aspartate, carbon dioxide, lactate and pyruvate were produced by both strains after incubation in medium supplemented with $\alpha$-lactose. The pathogenic strain produced more alanine, aspartate, carbon dioxide, lactate and pyruvate than the nonpathogenic strain (Table 2).

Maltose. The products alanine, aspartate, carbon dioxide, lactate and pyruvate were produced by the 2 strains after incubation for $48 \mathrm{~h}$ in medium containing maltose. Furthermore, the pathogenic strain produced more alanine, aspartate, carbon dioxide and 
pyruvate. In contrast, the nonpathogenic strain produced more lactate (Table 2).

Sucrose. After incubation for $48 \mathrm{~h}$ in medium supplemented with sucrose, the pathogenic and nonpathogenic Cryptobia salmositica produced alanine, aspartate, carbon dioxide, lactate and pyruvate. In addition, the pathogenic strain produced more alanine, carbon dioxide and pyruvate, while the nonpathogenic strain produced more lactate (Table 2). There was no difference in the amount of aspartate produced between the 2 strains after incubation in sucrose.

\section{Amino acids}

L-glutamine. Alanine, aspartate and lactate were produced by pathogenic and nonpathogenic Cryptobia salmositica after incubation in medium supplemented with the amino acid L-glutamine. Carbon dioxide and pyruvate were not produced by the pathogenic strain after a $48 \mathrm{~h}$ incubation in medium supplemented with L-glutamine. Furthermore, the amounts of alanine, aspartate and lactate which were produced were very low.

D-proline. Alanine, aspartate, lactate and pyruvate were produced by the 2 strains after incubation in medium containing the amino acid proline. Lactate was not produced by either strain after incubation in medium supplemented with proline. The nonpathogenic strain of Cryptobia salmositica produced more alanine and carbon dioxide, while no differences were detected in the levels of aspartate and pyruvate produced by the 2 strains (Table 2 ).

\section{DISCUSSION}

The main aim of the present study was to determine whether there were differences in the capacity of various monosaccharides, disaccharides and amino acids to support motility and multiplication in both pathogenic and nonpathogenic strains of Cryptobia salmositica. The results demonstrate that the pathogenic strain multiplied more readily in monosaccharides, while the nonpathogenic strain multiplied better in disaccharides. The only exception was the monosaccharide $\mathrm{D}(-)$ arabinose, for which there was not a significant difference between the 2 strains.

The carbohydrate metabolism of the pathogenic trypansomes of man and animals, and particularly that of Trypanosoma brucei, have been well studied. In its mammalian host, $T$. brucei is entirely dependent on glycolysis for ATP production, and pyruvate is the sole end product (Opperdoes 1987), while the procyclic stage metabolises glucose to produce carbon dioxide, acetate, succinate and alanine (Clayton \& Michels 1996). The procyclic form seems to prefer amino acids, such as proline or glutamic, rather than glucose. In another trypanosomatid, Phytomonas sp., glucose, mannose and fructose are the main carbohydrates used and the end products are acetate, pyruvate, glycerol, succinate and ethanol (Sanchez-Moreno et al. 1992). In the present study, the pathogenic strain of Cryptobia salmositica multiplied more readily in monosaccharides, and the highest numbers were obtained with either galactose or mannose in the culture medium. When C. salmositica (pathogenic strain) was incubated in each of these carbohydrates, more lactate than pyruvate was produced, although alanine, aspartate and carbon dioxide were produced as well, but in much lower quantities. In contrast, the nonpathogenic strain multiplied more readily in medium supplemented with disaccharides, and highest numbers were obtained when lactose was the carbohydrate source. Similar to the pathogenic strain, more lactate was produced than pyruvate. In general, respiration is seldom fully oxidative in any group of parasites, and often involves a 'metabolic switch' on changing from one stage to the next. For example, glycolysis to lactate is the major energy-producing pathway in the intracellular stages of Plasmodium and Babesia species that infect mammals; however, Plasmodium spp. that infect non-mammalian vertebrates are fully oxidative and excrete carbon dioxide as well as lactate. The present study suggests that $C$. salmositica is fully oxidative. However, further studies are needed to characterise these oxidative pathways. For example it would be useful to measure the production of acetate, ethanol, glycine, glycerol and succinate, under both aerobic (air and $95 \%$ oxygen $/ 5 \%$ carbon dioxide) and anaerobic (95\% nitrogen $/ 5 \%$ carbon dioxide and $100 \%$ nitrogen) conditions. The formation of succinate might suggest the incorporation of the pyruvate carbon skeleton into the Kreb's cycle.

Woo (1979) was the first investigator to continuously culture Cryptobia salmositica at $11^{\circ} \mathrm{C}$ with fetal calf serum in HEPES-buffered MEM supplemented with Hanks' salts. The parasites maintained the morphological appearance of bloodstream parasites and were infective to trout. Subsequently, Li \& Woo (1991) demonstrated that the parasite multiplied more readily and in larger numbers with L-glutamine and when $25 \%$ FBS or $10 \%$ trout serum was used instead of fetal calf serum (Ardelli \& Woo 1998). Ardelli \& Woo (1998) further improved the number of parasites in culture by increasing the buffering capacity of the culture medium. This was accomplished by increasing the amount of HEPES from 25 to $100 \mathrm{mM}$. Ardelli \& Woo (2001b) suggested that L-glutamine and glucose might be the limiting factors because the decline in parasite 
numbers in 'old' cultures was not related to a change to an acidic environment. Thus they suggested increasing the concentration of HEPES in order to increase the available $\mathrm{H}^{+}$, thereby stabilising the $\mathrm{pH}$ and favoring enhanced parasite multiplication. The results of the present study suggest that pathogenic and nonpathogenic strains of C. salmositica may have different carbohydrate requirements. The pathogenic strain prefers galactose or mannose, while the nonpathogenic strain prefers lactose. Thus, in addition to increasing the buffering capacity of media, using galactose or mannose (pathogen) and lactose (nonpathogenic) in place of glucose enhanced multiplication of C. salmositica. This may, in part, explain the multiplication of the nonpathogenic (vaccine) strain in Atlantic salmon (Ardelli \& Woo 2002), but not in rainbow trout (Li \& Woo 1990). Further studies are necessary to confirm this suggestion.

The consumption of glucose by kinetoplastids (e.g. Trypansoma brucei, T. cruzi, Leishmania spp. and Crithidia spp.) is characterised by the excretion of reduced products such as succinate, pyruvate, ethanol, L-alanine or lactate (depending on the species) under both anaerobic and aerobic conditions (Cazzulo 1992). Studies have shown that many Trypanosomatidae degrade glucose only partially to carbon dioxide, excreting into the medium a considerable part of the hexose carbon as organic acids (Hamm et al. 1990). The present study demonstrates that the piscine kinetoplastid parasite Cryptobia salmositica is capable of using numerous carbohydrates as carbon and energy sources. Similar to many other kinetoplastid parasites (e.g. Trypanosoma brucei, T. cruzi), it has been suggested that glucose is the preferred source of carbon and energy for C. salmositica in fishes (Li \& Woo 1991). However, the present in vitro study demonstrated that neither $\alpha$-D-glucose nor $\beta$-D(+)glucose are preferred sources of carbohydrate for pathogenic and nonpathogenic strains.

For many kinetoplastid parasites, the end products of glucose catabolism are different, and are influenced by the presence of oxygen and the developmental stage of the parasite. In the present study, Cryptobia salmositica (both pathogenic and nonpathogenic strains) under aerobic conditions produced alanine, aspartate, carbon dioxide, lactate and pyruvate. D-lactate is produced by at least 4 species of Leishmania, while Trypanosoma lewisi produces both isomers of lactate (Darling et al. 1988). In the present study, all the lactate produced by C. salmositica (either pathogenic or nonpathogenic strains) was L-lactate. This has been confirmed by earlier studies (Ardelli et al. 2000, Ardelli \& Woo 2001b), suggesting that the methylglyoxyl bypass is not operational in Cryptobia spp. Carbon dioxide was also produced by both strains of C. salmositica under aerobic conditions, and depended on the source of carbohydrate. Carbon dioxide measurement was not possible under a constant flow of nitrogen in the present study; thus, anaerobic conditions could not be produced. It would be interesting to study the metabolism of this parasite under conditions which simulate anaerobosis, e.g. using salicylhydroxamic acid (SHAM), an inhibitor of mitochondrial glycerophosphate oxidase, or sodium azide, an inhibitor of oxidative phosphorylation.

Monosaccharides with 5 or more carbons in the backbone usually occur in aqueous solution as cyclic (ring) structures, in which the carboxyl group has formed a covalent bond with the oxygen of a hydroxyl group along the chain. When D-glucose is crystallised from water, $\alpha$-D-glucose results. This differs in its optical activity from D-glucose crystallised from the solvent pyridine, a form known as $\beta$-D-glucose. However, the 2 forms are identical in chemical composition and they interconvert in aqueous solution. Thus, a solution of $\alpha$ D-glucose and a solution of $\beta$-D-glucose eventually form an identical equilibrium mixture which consists of about $1 / 3 \alpha$-D-glucose, $2 / 3 \beta$-D-glucose, and very small amounts of the linear form (El Khadem 1988). In the present study, $\alpha$-D-glucose was preferred over $\beta$ $\mathrm{D}(+)$ glucose by the pathogenic strain, while $\beta-\mathrm{D}(+)$ glucose was preferred over $\alpha$-D-glucose by the nonpathogenic strain. Carbon dioxide and lactate levels were low or below detectable levels when both strains were incubated in $\mathrm{D}(+)$ glucose, and were much higher than that produced with any other monosaccharide, with the exception of mannose. In contrast, when the pathogenic and nonpathogenic strains were incubated in $\beta$ $\mathrm{D}(+)$ glucose, there were apparent differences. Carbon dioxide produced by the pathogen was below detectable levels; however, lactate and pyruvate levels were very high, and lactate levels were much higher than pyruvate. In contrast, the pathogenic strain produced considerably more carbon dioxide.

Studying the nutritional requirements of various representative isolates could result in an improvement of in vitro growth, a better understanding of in vivo pathobiology of the parasite, and correlation of nutritional requirements with different taxonomic groups. It is not always easy to determine the precise pathways and to characterise these pathways in Cryptobia salmositica; further investigation is required to determine the precise stoichiometry of conversions, especially in cell-free extracts and their response in the presence of inhibitors. The presence of characteristic coenzymes and activators, and the labelling pattern in the final products for that pathway must still be determined. Also, it would be interesting to perform a complete carbon balance analysis by measuring the rates of substrate consumption and end-product formation. 
Acknowledgements. This study was supported by grants from the National Sciences and Engineering Research Council of Canada (NSERC).

\section{LITERATURE CITED}

Archer RK (1965) Haematological techniques for use on animals. Blackwell Scientific Publications, Oxford

Ardelli BF, Woo PTK (1998) Improved culture media for piscine hemoflagellates Cryptobia and Trypanosoma (Kinetoplastida). J Parasitol 84:1267-1271

Ardelli BF, Woo PTK (2001a) The in vitro effects of isometamidium chloride against Cryptobia salmositica. J Parasitol 87:194-202

Ardelli BF, Woo PTK (2001b) Metabolic byproducts of piscine hemoflagellates Cryptobia spp. (Kinetoplastida: Bodonidae) under in vitro conditions. Folia Parasitol (České Budéjovice) 48:187-191

Ardelli BF, Woo PTK (2002) Experimental Cryptobia salmositica infections in Atlantic salmon: cell-mediated and humoral immunity against pathogenic and nonpathogenic strains of the parasite. J Fish Dis 25:265-274

Ardelli BF, Witt JDS, Woo PTK (2000) Identification of glycosomes and metabolic end products in pathogenic and nonpathogenic strains of Cryptobia salmositica (Kinetoplastida: Bodonidae). Dis Aquat Org 42:41-51

Cazzulo JJ (1992) Aerobic fermentation of glucose by trypanosomatids. FASEB J 6:3153-3161

Clayton CE, Michels P (1996) Metabolic compartmentation in African trypanosomes. Parasitol Today 12:465-471

Darling TN, Balber AE, Blum JJ (1988) A comparative study of D-lactate and L-lactate formation by four species of Leishmania and of Trypanosoma lewisi and Trypanosoma brucei gambiense. Mol Biochem Parasitol 30:253-258

El Khadem (1988) Carbohydrate chemistry: monosaccharides and their oligomers. Academic Press, New York

Forrester RL, Wataji LJ, Silverman DA, Pierre KJ (1976) Enzymatic method for the determination of carbon dioxide in serum. Clin Chem 22:243

Frankel S (1970) Enzymes. In: Frankel S, Reitman S, Sonnenwirth AC (eds) Gradwohl's clinical laboratory methods and diagnosis, 7th edn. Mosby, St. Louis, p 120

Hamm B, Schlinder A, Mecke D, Duszento M (1990) Differentiation of Trypansoma brucei bloodstream trypomastogotes from long slender to short stumpy-like forms in axenic culture. Mol Biochem Parasitol 12:25-35

Editorial responsibility: Wolfgang Körting,

Hannover, Germany
Li S, Woo PTK (1991) In vitro effects of fetal bovine serum and glucose on multiplication of Cryptobia salmositica. J Parasitol 77:151-155

Li S, Woo PTK (1995) Efficacy of a live Cryptobia salmositica vaccine, and the mechanism of protection in vaccinated rainbow trout, Oncorhynchus mykiss, against cryptobiosis. Vet Immunol Immunopathol 48:343-353

Marbach EP, Weil MH (1967) Rapid enzymatic measurement of blood lactate and pyruvate. Clin Chem 13:314

Opperdoes FR (1987) Compartmentation of carbohydrate metabolism in trypanosomes. Annu Rev Microbiol 41: $127-141$

Paterson WB, Woo PTK (1983) Electron microscopic observations of the bloodstream form of Cryptobia salmositica Katz, 1951 (Kinetoplastida, Bodonina). J Protozool 39:431-437

Sanchez-Moreno M, Lasztity D, Coppens I, Opperdoes FR (1992) Characterization of carbohydrate metabolism and demonstration of glycosomes in a Phytomonas sp. isolated from Euphorbia characias. Mol Biochem Parasitol 54:185-200

Thomas PT, Ballantyne JS, Woo PTK (1992) In vitro oxygen consumption and motility of Cryptobia salmositica, Cryptobia bullocki and Cryptobia catostomi. J Parasitol 78: 747-749

Woo PTK (1979) Trypanoplasma salmositica, experimental infections in rainbow trout Salmo gairdneri. Exp Parasitol 47:36-48

Woo PTK (1991) Mammalian trypanosomiasis and piscine cryptobiosis in Canada and the United States. Bull Soc Vector Ecol 16:25-42

Woo PTK, Li S (1990) In vitro attenuation of Cryptobia salmositica and its use as a live vaccine against cryptobiosis in Oncorhynchus mykiss. J Parasitol 76:752-755

Woo PTK, Poynton SL (1995) Diplomonadida, Kinetoplastida and Amoebida (phylum Sarcomastigophora). In: Woo PTK (ed) Fish diseases and disorders. I. Protozoan and metazoan infections. CABI Publishing, Wallingford, p 27-96

Woo PTK, Thomas PT (1991) Polypeptide and antigen profiles of Cryptobia salmositica, C. bullocki and C. catostomi (Kinetoplastida: Sarcomastigophora) isolated from fishes. Dis Aquat Org 11:201-205

Zuo X, Woo PTK (1997) Proteases in pathogenic and nonpathogenic hemoflagellates, Cryptobia spp. (Sarcomastigophora: Kinetoplastida) of fishes. Dis Aquat Org 29: $57-65$

Submitted: April 15, 2002; Accepted: March 5, 2003 Proofs received from author(s): August 4, 2003 